\title{
ТЕПЛОВЫЕ ПОТЕРИ ПРИ ПРЕВЫШЕНИИ ТЕМПЕРАТУРНОГО РЕЖИМА ОБРАТНОЙ СЕТЕВОЙ ВОДЫ В СИСТЕМЕ ТЕПЛОСНАБЖЕНИЯ ПРЕДПРИЯТИЙ
}

Горбунова Т.Г. ФГБОУ ВО «Казанский государственный энергетический университет», г. Казань, Россия

В статье уделяется внимание проблеме возврата обратной сетевой воды в системе теплоснабжения с повышенным температурным режимом. Автором изучаются количественные показатели тепловых потерь относительно конкретного города при изменении температуры теплоносителя выше проектного значения.

Ключевые слова: обратная сетевая вода, температурный график, тепловые потери, эффективность теплоснабжения, тепловые сети, система теплоснабжения.

На протяжении последних лет наблюдает последовательное изменение принятого в советском союзе температурного графика для систем централизованного теплоснабжения. Понижение температурного графика на источниках теплоты официально оформляется, как работа по проектному графику $150 / 70^{\circ} \mathrm{C}$ со «срезкой» при пониженной температуре $110 \ldots 130^{\circ} \mathrm{C}$. Переход к энергосберегающей политике, температурные изменения климата с тенденцией к потеплению, строительство собственных источников тепла крупными промышленными потребителями частично объясняет снижение температуры в подающей сети, однако негативно сказывается на взаимослаженной работе протяженных транспортных сетей и внутренних тепловых пунктов потребителей тепловой энергии.

Анализ фактических температурных режимов отпуска тепла с сетевой водой от источников города в тепловые сети и их соответствие утвержденным графикам регулирования отпуска тепла выполнялся по данным учета за 2018 г. по г.Казань. Как видно из графика (рис.1), имеет место превышение фактических температур сетевой воды в обратном трубопроводе в диапазоне температур наружного воздуха от - 11 до $7^{\circ} \mathrm{C}$ в пределах более чем на $5 \%$ по сравнению со значениями по утвержденному графику [2].

Однако, в соответствии с п. 6.2.59 «Правил технической эксплуатации тепловых энергоустановок» отклонение заданной графиком фактической среднесуточной температуры обратной сетевой воды может быть не более чем на $5 \%$. 


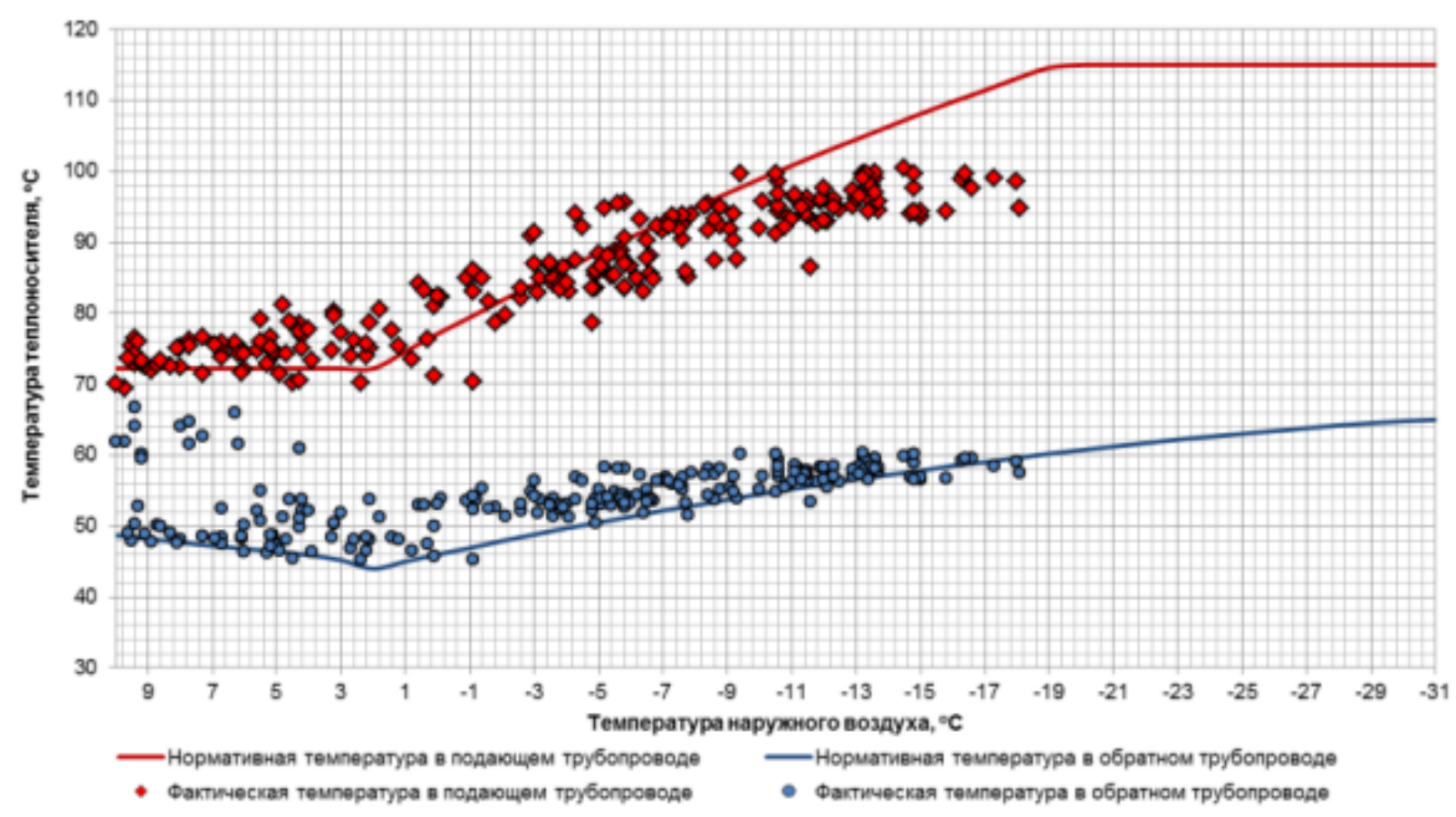

Рис. 1 - Утвержденный и фактический график отпуска тепловой энергии с сетевой водой от КТЭЦ-1 за 2018 г.

Нормативные тепловые потери одним метром трубопроводов в грунте при транспортировке теплоносителя определяют по формуле [1].

$$
q_{1}^{L}=\frac{\left(t_{\mathrm{s} 1}-t_{\mathrm{s} 2}\right)\left(R_{\mathrm{u} 32}^{L}-R_{\mathrm{tp} 2}^{\mathrm{K}}\right)-\left(t_{\mathrm{s} 2}-t_{\mathrm{H}}\right) R_{0}}{\left(R_{\mathrm{u} 31}^{L}-R_{\mathrm{Tp} 1}^{\mathrm{K}}\right)\left(R_{\mathrm{us} 2}^{L}+R_{\mathrm{Tp} 2}^{\mathrm{K}}\right)-R_{0}^{2}} K
$$

Принимая температуру грунта $7,8^{\circ} \mathrm{C}$ и $0,02^{\circ} \mathrm{C}$ и теплоносителя $45^{\circ} \mathrm{C}$ и $55^{\circ} \mathrm{C}$ для отопительного и неотопительного периода соответственно, можно определить тепловые потери одним метром трубопровода в час.

Следовательно, тепловые потери через изоляцию трубопровода при изменении температуры теплоносителя на 1 градус от проектного значения составят (рис. 2). 


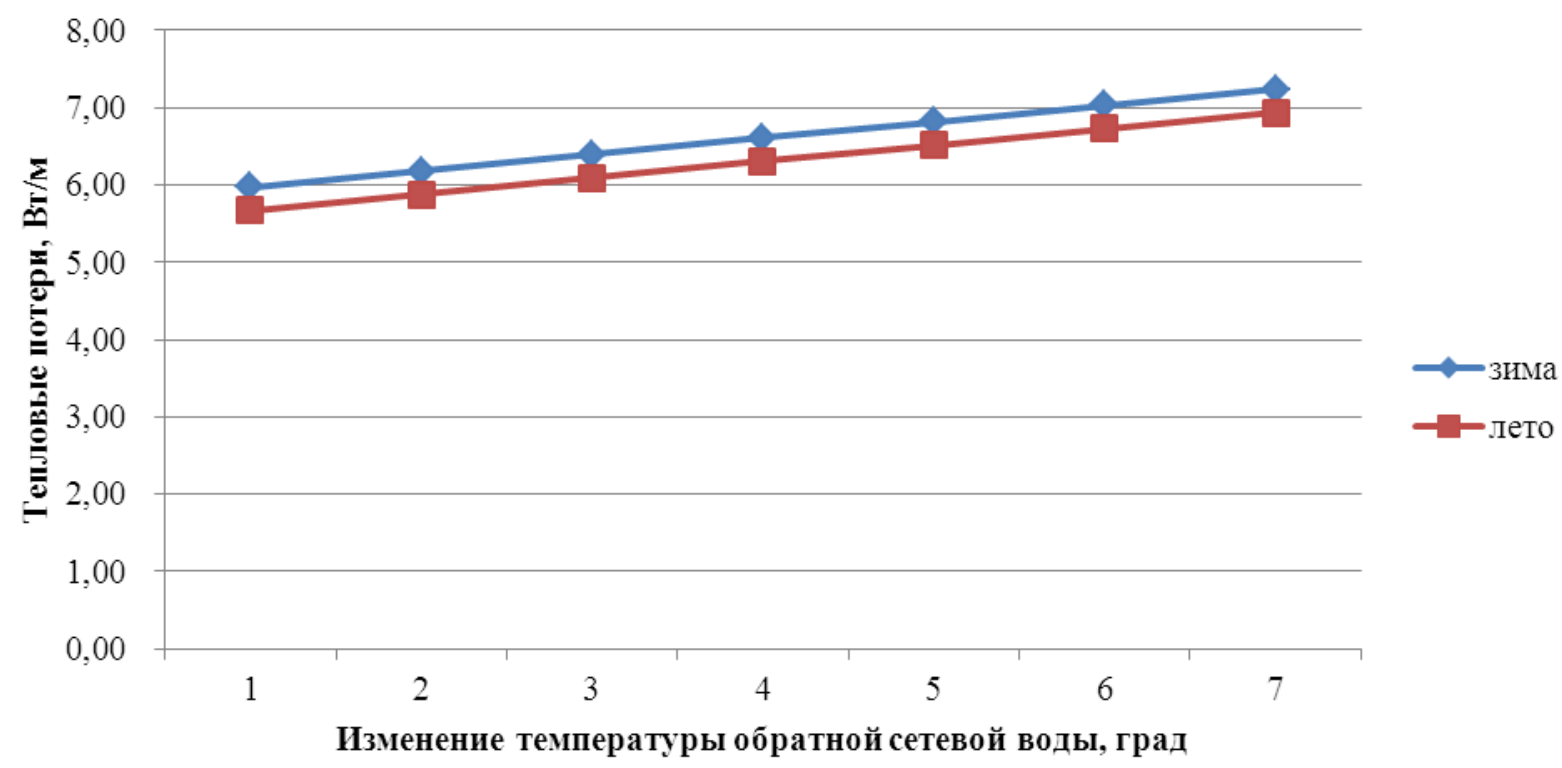

Рис. 2 - Влияние температуры теплоносителя на тепловые потери через изоляцию

Исходя из данных графика видно, что увеличиваются удельные тепловые потери через изоляцию трубопровода в зависимости от роста температуры обратной сетевой воды. Рост тепловых потерь отрицательно сказывается на энергоэффективности системы теплоснабжения, а также может привести к гидравлическому дисбалансу системы и появлению «перетопов» и «недотопов» у конечного потребителя.

Одними из способов решения проблемы возникающего температурного отклонения обратной сетевой воды являются $[3,4,5]$ :

1. Устранение возможных ошибок при проектировании и монтаже внутридомовой системы регулирования теплоносителя.

2. Проверка исправности и правильности регулировки теплотехнического оборудования тепловых пунктов.

3. Проверка технического состояния внутренних систем теплоснабжения в случае факта о техническом (физическом) износе оборудования.

4. Обучение обслуживающего персонала правилам наладки внутридомовых систем отопления.

\section{Список литературы:}

1. СП 41-103-2000 Проектирование тепловой изоляции оборудования и трубопроводов.

2. Схема теплоснабжения г.Казани на период по 2034 г. Актуализированная версия. Глава 1.Существующее положение в сфере производства, передачи и потребления тепловой энергии для целей теплоснабжения.

3. Киселев Н.Н Факторы, влияющие на температуру обратной сетевой воды//Новости теплоснабжения, №10 (206), 2017 г. 
4. Горбунова Т.Г., Ваньков Ю.В., Медяков А.А. НАДЕЖНОСТЬ ТЕПЛОВЫХ СЕТЕЙ: ТЕОРИЯ И ПРАКТИКА. Надежность и безопасность энергетики. 2017;10(4):275-279.

5. Ваньков Ю.В., Горбунова Т.Г., Загидуллин Д.Н. «Схема теплоснабжения г.Набережные Челны: анализ надежности кольцевых тепловых сетей северо-восточной части города» // тр. XIII Междунар.симп. «Энегоресурсоэффективность и энергосбережение в РТ», Казань, 5-7 декабря 2012г., Издательство ООО «Скрипта», 2012г. - 512с. 